\title{
Increased risk for ischaemic events is related to combined RAS polymorphism
}

P P van Geel, Y M Pinto, A H Zwinderman, R H Henning, A J van Boven, J W Jukema, A V G Bruschke, J J P Kastelein, W H van Gilst, on behalf of the REGRESS Study Group

\begin{abstract}
Objective-To determine whether the angiotensin converting enzyme (ACE) and the angiotensin II type 1 receptor $\left(\mathrm{AT}_{1} \mathrm{R} \mathrm{A} 1166 \mathrm{C}\right)$ gene polymorphism interact to increase the risk of ischaemic events, and whether this can be explained by the progression of angiographically defined coronary atherosclerosis.

Design-Prospective defined substudy of the lipid lowering regression trial (REGRESS).

Setting-University hospital.

Patients-885 male patients with stable coronary artery disease.

Main outcome measures-Incidence of ischaemic events during a two year follow up; serial quantitative coronary arteriography (mean segment diameter and minimum obstruction diameter) at baseline and after two years.

Results-Patients who carried both the ACE-DD and AT ${ }_{1}$ R-CC genotype had significantly more ischaemic events during the two year follow up than those carrying other genotype combinations ( $p=0.035$, Mantel-Haenszel test for linear association). There was no association between the two genotypes and mean segment diameter or minimum obstruction diameter at baseline or after two years.

Conclusions-The suggestion that ACE-DD and AT ${ }_{1}$ R-CC genotypes interact to increase the risk of ischaemic events is confirmed. However, this increased risk was not accompanied by increased progression of angiographically defined coronary atherosclerosis.

(Heart 2001;85:458-462)
\end{abstract}

Keywords: renin-angiotensin system; polymorphism; coronary atherosclerosis; ischaemic events

Department of

Cardiology, University of Groningen,

Antonius Deusinglaan

1, 9713 AV Groningen,

Netherlands

P P van Geel

$Y M$ Pinto

A J van Boven

W $\mathrm{H}$ van Gilst

Department of Clinical Pharmacology,

University Hospital

Groningen

R H Henning

Department of

Medical Statistics,

University of Leiden,

Leiden, Netherlands

A $\mathrm{H}$ Zwinderman

Department of

Cardiology, Leiden

University Medical

Centre

J W Jukema

A V G Bruschke

Department of

Vascular Medicine,

Academic Medical

Centre, Amsterdam,

Netherlands

J J P Kastelein

Correspondence to:

Dr van Geel

p.p.geel@med.rug.nl

Accepted 8 November 2000
Polymorphism of the renin-angiotensin system (RAS) are reported to play a role in the development of various cardiovascular diseases. A polymorphism in the 16 th intron of the angiotensin converting enzyme (ACE) gene, which is associated with higher ACE concentrations, ${ }^{1}{ }^{2}$ is reported to be a risk factor for myocardial infarction $^{3-5}$ and post-infarct cardiac dilatation, ${ }^{6}$ although another study has not found such an association. ${ }^{7}$ An adenine/cytosine $(\mathrm{A} / \mathrm{C})$ base substitution at position 1166 in the angiotensin II type 1 receptor $\left(\mathrm{AT}_{1} \mathrm{R}\right)$ has been associated with essential hypertension, ${ }^{8}$ increased coronary artery vasoconstriction, ${ }^{9}$ and cardiac hypertrophy. ${ }^{10}$ Although both polymorphism seem to be associated with cardiovascular disease, only two studies have reported an interaction between them. ${ }^{11}{ }^{12}$

It is therefore unclear at present whether an interaction between these two polymorphism is related to complications of atherosclerosis, or which underlying mechanism might be responsible. One could speculate that the mechanism involved is explained by the occurrence of a sudden thromboembolic processes, such as increased plaque instability, or conversely by the gradual progression of established coronary lesions.

We hypothesised that both polymorphism synergistically increase RAS activity, thereby increasing the risk of ischaemic events by augmented progression of coronary atherosclerosis. Therefore we genotyped male patients who were participating in the lipid lowering regression trial, REGRESS (regression growth evaluation statin study). ${ }^{13}$ In this study, the analysis of genetic factors that might contribute to the progression of coronary artery disease was defined prospectively.

\section{Methods}

STUDY DESIGN

The genotype for $\mathrm{ACE}$ and $\mathrm{AT}_{1} \mathrm{R}$ was determined in patients included in the REGRESS trial. ${ }^{13}$ REGRESS is a double blind, placebo controlled multicentre (Netherlands) study to assess the effect of two years of treatment with the 3-hydroxy-3-methylglutaryl-coenzyme A (HMG-CoA) reductase inhibitor pravastatin on angiographically documented coronary atherosclerosis. The study involves 885 male patients with coronary artery disease with serum cholesterol ranging between $4-8 \mathrm{mmol} / 1$ and triglycerides $<4.0 \mathrm{mmol} / \mathrm{l}$.

The REGRESS study was conducted under the auspices of the Interuniversity Cardiology Institute of the Netherlands (ICIN), Utrecht, Netherlands. Written informed consent was obtained from all patients.

\section{LIPIDS AND LIPOPROTEINS}

All lipid laboratory tests were carried out at the Lipid Reference Laboratory, as published previously. ${ }^{13}$

\section{CLINICAL EVENTS}

The following clinical events were analysed during the study and identified before unblinding: myocardial infarction (fatal or non-fatal); coronary heart disease death; non-scheduled 
Table 1 Baseline characteristics according to the $A C E$ and $A T_{1} R$ genotypes

\begin{tabular}{|c|c|c|c|c|c|}
\hline ACE DD genotype: & - & + & - & + & \\
\hline$A T_{1} R C C$ genotype: & - & - & + & + & $p$ Value \\
\hline Number of patients & 522 & 180 & 47 & 25 & \\
\hline Age (years) & $56(8)$ & $56(8)$ & $56(8)$ & $56(8)$ & 0.99 \\
\hline $\mathrm{BMI}\left(\mathrm{kg} / \mathrm{m}^{2}\right)$ & $26.0(2.7)$ & $26.0(2.6)$ & $26.3(2.5)$ & $25.9(3.3)$ & 0.93 \\
\hline Ever smoked (\%) & 89 & 85 & 86 & 88 & 0.67 \\
\hline $\mathrm{SBP}(\mathrm{mm} \mathrm{Hg})$ & $135(19)$ & $136(19)$ & $136(15)$ & $134(19)$ & 0.89 \\
\hline $\mathrm{DBP}(\mathrm{mm} \mathrm{Hg})$ & $81(10)$ & $82(10)$ & $83(9)$ & $81(8)$ & 0.75 \\
\hline Total cholesterol $(\mathrm{mmol} / \mathrm{l})$ & $6.0(0.9)$ & $6.1(0.9)$ & $6.0(0.8)$ & $6.1(0.8)$ & 0.66 \\
\hline LDL cholesterol $(\mathrm{mmol} / \mathrm{l})$ & $4.3(0.8)$ & $4.3(0.8)$ & $4.2(0.7)$ & $4.4(0.7)$ & 0.75 \\
\hline HDL cholesterol $(\mathrm{mmol} / \mathrm{l})$ & $0.93(0.23)$ & $0.91(0.22)$ & $0.91(0.19)$ & $0.94(0.25)$ & 0.85 \\
\hline Triglycerides $(\mathrm{mmol} / \mathrm{l})$ & $1.79(0.77)$ & $1.88(0.76)$ & $1.76(0.77)$ & $1.70(0.83)$ & 0.50 \\
\hline Baseline MSD (mm) & $2.72(0.36)$ & $2.75(0.40)$ & $2.75(0.43)$ & $2.71(0.38)$ & 0.86 \\
\hline Baseline MOD (mm) & $1.75(0.35)$ & $1.76(0.36)$ & $1.83(0.41)$ & $1.68(0.28)$ & 0.39 \\
\hline Ejection fraction (\%) & $71(12)$ & $70(12)$ & $70(14)$ & $70(14)$ & 0.97 \\
\hline \multicolumn{6}{|l|}{ Extent of heart disease (\%) } \\
\hline 1 vessel & 42 & 43 & 51 & 24 & \\
\hline 2 vessels & 35 & 32 & 21 & 40 & 0.26 \\
\hline 3 vessels & 23 & 25 & 28 & 36 & \\
\hline$\beta$ Blocking agent (\%) & 74 & 74 & 75 & 80 & 0.93 \\
\hline Calcium antagonist $(\%)$ & 60 & 61 & 64 & 48 & 0.61 \\
\hline Nitrates $(\%)$ & 56 & 52 & 57 & 56 & 0.80 \\
\hline
\end{tabular}

Values are mean (SD) unless stated otherwise.

$\mathrm{ACE}$, angiotensin converting enzyme; $\mathrm{AT}_{1} \mathrm{R}$, angiotensin II type 1 receptor; BMI, body mass index; DBP, diastolic blood pressure; HDL, high density lipoprotein; LDL, low density lipoprotein; MOD, minimum obstruction diameter; MSD, mean segment diameter; SBP, systolic blood pressure.

Table 2 Change in lipids and lipoproteins in relation to the $A C E$ and $A T_{1} R$ genotypes for patients randomised to placebo or pravastatin treatment

\begin{tabular}{|c|c|c|c|c|c|}
\hline ACE DD genotype: & - & + & - & + & \\
\hline$A T_{1} R C C$ genotype: & - & - & + & + & $p$ Value \\
\hline \multicolumn{6}{|l|}{ Placebo } \\
\hline Number of patients & 232 & 85 & 26 & 15 & \\
\hline Total cholesterol $(\mathrm{mmol} / \mathrm{l})$ & $0.18(0.72)$ & $0.09(0.82)$ & $0.06(0.56)$ & $0.11(1.01)$ & 0.73 \\
\hline HDL cholesterol $(\mathrm{mmol} / \mathrm{l})$ & $0.03(0.15)$ & $0.03(0.14)$ & $0.01(0.13)$ & $0.05(0.26)$ & 0.85 \\
\hline $\begin{array}{l}\text { LDL cholesterol } \\
(\mathrm{mmol} / \mathrm{l})\end{array}$ & $0.04(0.67)$ & $-0.01(0.65)$ & $-0.13(0.48)$ & $-0.07(0.79)$ & 0.56 \\
\hline Triglycerides $(\mathrm{mmol} / \mathrm{l})$ & $0.21(0.81)$ & $0.12(0.74)$ & $0.40(0.84)$ & $0.53(0.98)$ & 0.20 \\
\hline \multicolumn{6}{|l|}{ Pravastatin } \\
\hline Number of patients & 252 & 82 & 20 & 9 & \\
\hline Total cholesterol $(\mathrm{mmol} / \mathrm{l})$ & $-1.31(0.86)$ & $-1.46(0.77)$ & $-1.17(1.11)$ & $-0.87(0.82)$ & 0.14 \\
\hline HDL cholesterol $(\mathrm{mmol} / \mathrm{l})$ & $0.11(0.17)$ & $0.09(0.18)$ & $0.11(0.16)$ & $-0.01(0.08)$ & 0.26 \\
\hline $\begin{array}{l}\text { LDL cholesterol } \\
(\mathrm{mmol} / \mathrm{l})\end{array}$ & $-1.36(0.78)$ & $-1.46(0.64)$ & $-1.28(0.92)$ & $-0.90(0.94)$ & 0.23 \\
\hline Triglycerides (mmol/l) & $-0.13(0.73)$ & $-0.22(0.67)$ & $-0.02(0.84)$ & $-0.06(0.61)$ & 0.52 \\
\hline
\end{tabular}

Values are mean change (SD). Change is defined as follow up measurement minus baseline measurement.

percutaneous transluminal coronary angioplasty (PTCA) or coronary artery bypass grafting (CABG); stroke and transient ischaemic attack; death from unknown cause.

QUANTITATIVE CORONARY ARTERIOGRAPHY

Serial coronary angiograms at baseline and after two years were analysed quantitatively using a cardiovascular measurement system (MEDIS Medical Imaging Systems, Nuenen, Netherlands). The quantitative coronary arteriographic procedures are described in detail elsewhere. ${ }^{13}$ Primary end points were:

- Change in average minimum obstruction diameter per patient (this variable mainly reflects focal progression-regression of atherosclerosis).

- Change in average mean segment diameter per patient (this variable mainly reflects diffuse progression-regression of atherosclerosis).

Minimum obstruction diameter and mean segment diameter denote angiograpically defined coronary atherosclerosis. As previously, ${ }^{13}$ we only analysed the changes in lesions and segments not influenced by angioplasty or bypass grafting.

GENOTYPING OF THE ACE AND AT ${ }_{1} r$ genes

Blood samples for DNA studies were obtained before randomisation. Thus DNA samples were available for prospectively defined purposes. Genomic DNA was extracted from white blood cells. The method used for genotyping of the ACE I/D polymorphism is a modification of that described by Rigat and colleagues. ${ }^{14}$ To avoid mistyping heterozygotes, the DD genotype was confirmed by an additional polymerase chain reaction (PCR) with the same protocol but a separate sense primer specific for the insertion allele: 5'TTT.GAG.ACG.GAG.TCT.CGC.TC. ${ }^{15}$ The $\mathrm{AT}_{1} \mathrm{R}$ polymorphism was identified by a mismatch PCR/restriction fragment length polymorphism strategy. ${ }^{16}$ PCR products were separated by agarose gel electrophoresis.

\section{STATISTICAL ANALYSIS}

Patients were grouped according to ACE and $\mathrm{AT}_{1} \mathrm{R}$ genotype and compared with each other for relevant baseline characteristics, change in lipid values, and changes in angiographic indices. Differences with respect to baseline variables were determined by analysis of variance and logistic regression as appropriate. The changes in lipid values and angiographic indices were assessed by a two way covariance analysis with randomised treatment (placebo or pravastatin) and the $\mathrm{ACE}$ and $\mathrm{AT}_{1} \mathrm{R}$ genotypes and baseline values as covariates. An intention to treat analysis was judged unlikely to be of additional value. The occurrence of events was analysed using Cox regression. A probability $p$ value of $p \leqslant 0.05$ was considered significant.

\section{Results}

BASELINE CHARACTERISTICS

Of the 885 patients from the REGRESS trial, genotyping was possible in $774 ; 394$ of these received pravastatin and 380 placebo. Table 1 shows the baseline characteristics for patients not homozygous for the ACE-D and $\mathrm{AT}_{1} \mathrm{R}-\mathrm{C}$ allele (-/-), homozygous for only the ACE-D allele $(+/-)$, homozygous for only the $\mathrm{AT}_{1} \mathrm{R}-\mathrm{C}$ allele $(-/+)$, or homozygous for both the ACE-D and $\mathrm{AT}_{1} \mathrm{R}-\mathrm{C}$ allele $(+/+)$. Neither the interaction between $\mathrm{ACE}-\mathrm{D}$ and $\mathrm{AT}_{1} \mathrm{R}-\mathrm{C}$ alleles nor that between ACE-D and $\mathrm{AT}_{1} \mathrm{R}-\mathrm{C}$ alleles showed any significance.

\section{CHANGE OF LIPIDS AND LIPOPROTEINS}

The lipid lowering effect of pravastatin was similar in the genotype groups of both polymorphism (table 2).

\section{CLINICAL EVENTS}

There was no significant difference between genotypes with respect to the effect of lipid lowering treatment on the incidence of clinical events (Cox regression interaction test, $p=0.62)$. We therefore we pooled the two treatment groups to assess any differences between genotypes in the incidence of clinical events. Patients with the ACE-DD/AT 1 R-CC 


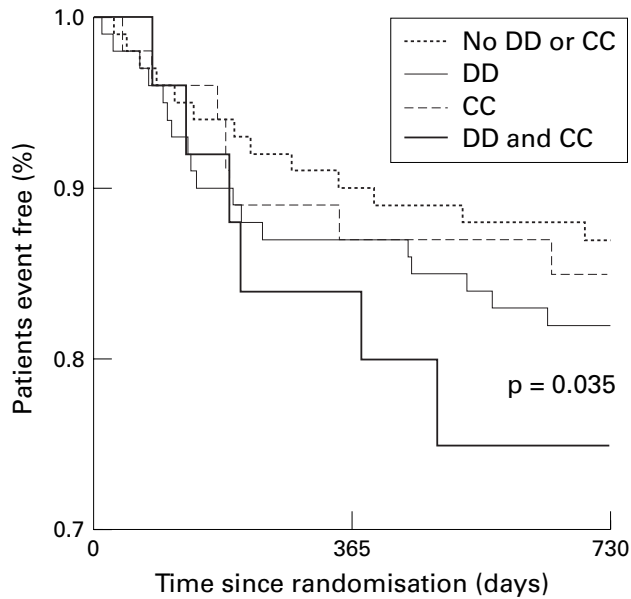

Figure 1 Kaplan-Meier curves for the event-free survival of patients according to $A C E-D D$ and $A T_{1} R-C C$ genotypes. The $p$ value indicates the overall significance of the Mantel-Haenszel test for linear association between the curves.

genotype combination had significantly more ischaemic events during the two year follow up ( $\mathrm{p}=0.035$ by the Mantel-Haenszel test for linear association (fig 1)). The relative risk of ischaemic events of each separate polymorphism was: ACE (DD v II/ID), 1.49 (95\% confidence interval (CI) 1.01 to 2.20), $\mathrm{p}=0.047 ;$ and $\mathrm{AT}_{1} \mathrm{R}$ (CC $\left.v \mathrm{AA} / \mathrm{AC}\right), 1.42$ (95\% CI 0.81 to 2.48 ), $\mathrm{p}=0.22$.

ANGIOGRAPHIC RESULTS

Because of patient dropouts and revascularisations, follow up angiography was available in 587 patients only. ${ }^{13}$ There was a mean (SD) of 6.6 (3.0) segments analysed in each patient. As shown in table 1, patients homozygous for both the ACE-D and the $\mathrm{AT}_{1} \mathrm{R}-\mathrm{C}$ allele showed no differences in angiographically defined coronary atherosclerosis (minimum obstruction diameter and mean segment diameter) at baseline compared with patients not homozygous for the ACE-D and $\mathrm{AT}_{1} \mathrm{R}-\mathrm{C}$ allele.

There was no significant difference between genotypes with respect to the effect of lipid lowering treatment on changes in minimum obstruction diameter and mean segment diameter during the trial $(\mathrm{p}=0.69$ and $\mathrm{p}=0.78$, respectively); thus the two treatment groups were pooled in order to assess the difference between genotypes with respect to changes in these variables.

The changes (follow up minus baseline) in mean segment diameter (MSD) and minimum obstruction diameter (MOD) after two years $(\mathrm{mm}$; mean (SD)) were as follows ( $\mathrm{p}=0.41$ for MSD and $\mathrm{p}=0.03$ for MOD):

- not homozygous for the ACE-D and $\mathrm{AT}_{1} \mathrm{R}-\mathrm{C}$ alleles $(\mathrm{n}=394): \quad \mathrm{MSD}, 0.08$ (0.20); MOD, 0.09 (0.23);

- homozygous for only the ACE-D allele $(\mathrm{n}=135)$ : MSD, 0.09 (0.16); MOD, 0.16 (0.44);

- homozygous for only the $\mathrm{AT}_{1} \mathrm{R}-\mathrm{C}$ allele $(\mathrm{n}=43)$ : MSD, 0.11 (0.19); MOD, 0.11 (0.19);

- homozygous for both the ACE-D and the $\mathrm{AT}_{1} \mathrm{R}-\mathrm{C}$ allele $(\mathrm{n}=15)$ : MSD, $0.01(0.20)$; MOD, -0.05 (0.21).
Patients homozygous for the ACE-D and $\mathrm{AT}_{1} \mathrm{R}-\mathrm{C}$ allele showed the least progression of angiographically defined coronary atherosclerosis in comparison with the other genotype combinations.

\section{Discussion}

Our study shows that in male patients with established coronary artery disease the combination of ACE-DD and $\mathrm{AT}_{1} \mathrm{R}-\mathrm{CC}$ genotypes is a risk factor for recurrent ischaemic events. This increased risk did not result from increased progression of angiographically defined coronary atherosclerosis.

The pathophysiological mechanism involved in the relation between the ACE deletion genotype and the $\mathrm{AT}_{1} \mathrm{R}-\mathrm{CC}$ genotype on ischaemic events cannot be deduced from our study. However, patients carrying both the ACE-DD and the $\mathrm{AT}_{1} \mathrm{R}-\mathrm{CC}$ genotype showed the smallest increase in progression of coronary atherosclerosis. Therefore it seems justified to conclude that the increase in event number in this group is not caused by increased progression of coronary atherosclerosis.

ACE and angiotensin II are important constituents of advanced coronary atherosclerotic lesions. ${ }^{17}$ Enhanced production of local angiotensin II by ACE stimulates adhesion molecule expression and increases oxidative stress, one of the triggering mechanisms of acute coronary syndromes. ${ }^{18}$ In ruptured coronary plaques, enhanced ACE expression is found in macrophages accumulating around the attenuated fibrous cap. ${ }^{19}$ Angiotensin II can induce proinflammatory cellular activity in human coronary atherosclerotic plaques and can raise concentrations of soluble intercellular adhesion molecule-1, suggesting a possible involvement of the RAS in inflammation and plaque instability. ${ }^{20}{ }^{21}$ It has been proposed that the higher tissue ACE activity found in patients with the ACE-DD genotype may increase plaque instability. ${ }^{22}{ }^{23}$ Although both polymorphism are associated with increased RAS activity, ${ }^{1292425}$ no association was found with progression of coronary atherosclerosis in the present study. One could speculate that increased RAS activity leads to increased plaque instability (oxidative stress, proinflammation), and therefore this could be one of the reasons why patients with both a higher tissue ACE activity (DD patients) and an increased angiotensin II susceptibility (CC patients) have more recurrent ischaemic events. In line with this, it is of interest that the HOPE (heart outcomes prevention evaluation) trial confirms a potential plaque stabilising effect of RAS inhibition by showing that ramipril reduced morbidity and mortality in patients with severe vascular disease. $^{26}$

Although patients with the ACE-DD and the $\mathrm{AT}_{1} \mathrm{R}-\mathrm{CC}$ genotype are more susceptible to ischaemic events, the "regression" of the minimum obstruction diameter in the two years of follow up is surprising. We cannot suggest a reason for this. However, some caution is needed in the interpretation of the findings, as the group of patients homozygous for both the ACE-D and the $A T_{1} R-C$ allele was rather 
small. Furthermore, only patients without an event were evaluated angiographically after two years, while patients with an event received no follow up. This means that selection of patients could have occurred. As the event rate was highest in patients with the ACE-DD and -CC genotypes, the drop out percentage was also the highest in that group in relation to angiographic follow up after two years. This drop out group could have biased our results on the progression/regression of atherosclerosis found in patients with the ACE-DD and $\mathrm{AT}_{1} \mathrm{R}-\mathrm{CC}$ genotypes after two years, leading to the surprising "regression" of MOD.

Others have previously attempted to link the $\mathrm{ACE}-\mathrm{DD}$ and $\mathrm{AT}_{1} \mathrm{R}-\mathrm{CC}$ genotypes to the progression of coronary atherosclerosis. ${ }^{527-29} \mathrm{Al}-$ though there seems to be a positive association, negative studies have also been reported. Several factors may account for these conflicting data - for example, the retrospective nature of the analyses, the low prevalence of the $\mathrm{AT}_{1} \mathrm{R}-\mathrm{CC}$ genotype, and small sample size. In most reports, coronary angiography was defined at one time point, making it difficult to judge the progression of atherosclerosis over time. To our knowledge this present prospective study is the first to involve repeated computer assisted angiography in a well defined and substantial sample. Despite the limitations of the technique, it seems justified to conclude that the ACE-DD and $\mathrm{AT}_{1} \mathrm{R}-\mathrm{CC}$ genotypes, either separately or in combination, are not associated with progression of angiographically defined coronary atherosclerosis.

\section{LIMITATIONS}

A limitation of the present study is the lack of ACE activity data, which would have substantiated any relation between the DD genotype, ACE activity, and events. As the ACE deletion genotype is reported to be associated with higher ACE activity, ${ }^{12}$ it may be assumed that this relation also existed in our patients.

It could be argued that we should have studied the progression/regression data on an intention to treat basis. Patients with cardiovascular death or myocardial infarction would then have been considered as having a total occlusion in one coronary segment. However, for our quantitative coronary arteriography, the coronary tree was divided into 13 segments according to the American Heart Association classification, excluding the posterolateral branches. Because angioplasty and coronary artery bypass procedures may influence progression considerably, lesions and segments modified by PTCA and CABG were excluded from the analysis. In the primary REGRESS study, 4209 coronary segments (6.6 (3.0) per patient) were measured quantitatively and included in the primary analysis. During the two year follow up of the study, only 28 of 885 patients suffered a myocardial infarct or other coronary heart disease event leading to death. It was considered that an intention to treat analysis which included 28 infarct related segments on top of the 4209 segments already evaluated would not to add substantially to the study, so it was not done.
CONCLUSIONS

The combination of the ACE-DD and the $\mathrm{AT}_{1} \mathrm{R}-\mathrm{CC}$ genotypes is a risk factor for recurrent ischaemic events in male subjects with established coronary artery disease. This increased risk is not related to an increased rate of progression of coronary lesions. As both polymorphism are associated with increased activity of the renin-angiotensin system but are not associated with increased progression of coronary atherosclerosis, increased plaque instability could be one of the reasons why these patients are at increased risk of recurrent ischaemic events.

We thank Hendrik Buikema PhD for his critical review and helpful suggestions. The REGRESS study was conducted under the auspices of the Interuniversity Cardiology Institute of the Netherlands (ICIN), Utrecht, Netherlands and supported by Bristol Myers Squibb Company, Princeton, New Jersey, USA. This study was supported by grant number $950-10-642$ of the Netherlands Organisation for Scientific Research (NWO), Netherlands.

1 Rigat B, Hubert C, Alhenc-Gelas F, et al. An insertion/ deletion polymorphism in the angiotensin I-converting enzyme gene accounting for half the variance of serum enzyme levels. I Clin Invest 1990;86:1343-6.

2 Tiret L, Rigat B, Visvikis S, et al. Evidence, from combined and linkage analysis that a variant of the angiotensin -converting enzyme (ACE) gene controls plasma ACE levels. Am f Hum Genet 1992;51:197-205.

3 Cambien F, Poirier O, Lecerf L, et al. Deletion polymorphism in the gene for angiotensin-converting enzyme is a potent risk factor for myocardial infarction. Nature 1992;359:641-4.

4 Tiret L, Kee F, Poirier O, et al. Deletion polymorphism in the angiotensin converting enzyme gene is associated with a parental history of myocardial infarction. Lancet 1993; 341:991-2.

5 Arbustini E, Grasso M, Fasani R, et al. Angiotensin converting enzyme gene deletion allele is independently and strongly associated with coronary atherosclerosis and myocardial infarction. Br Heart f 1995;74:584-91.

6 Pinto YM, van Gilst WH, Kingma JH, et al. The deletion-type allele of the angiotensin converting enzyme is associated with progressive ventricular dilatation after anterior myocardial infarction. $\mathcal{F}$ Am Coll Cardiol 1995;25: 1622-6.

7 Lindpaintner K, Pfeffer MA, Kreutz R, et al. A prospective evaluation of an angiotensin-converting-enzyme gene poly-
morphism and the risk of ischemic heart disease. N Engl 7 Med 1995;332:706-11.

8 Bonnardeaux A, Davies E, Jeunemaitre X, et al. Angiotensin II type 1 receptor gene polymorphism in human essential hypertension. Hypertension 1994;24:63-9.

9 Amant C, Hamon M, Bauters C, et al. The angiotensin II Amant $C$, Hamon $M$, Bauters C, et al. The angiotensin II
type 1 receptor gene polymorphism is associated with coronary artery vasoconstriction. f $\mathrm{Am}$ Coll Cardiol coronary artery

10 Osterop APRM, Kofflard MJM, Sandkuijl LA, et al. $\mathrm{AT}_{1}$ Receptor $\mathrm{A} / \mathrm{C}^{1166}$ polymorphism contributes to cardiac hypertrophy in subjects with hypertrophic cardiomyopathy. Hypertension 1998;32:825-30.

11 Tiret L, Bonnardeaux A, Poirier O, et al. Synergistic effects of angiotensin-converting enzyme and angiotensin-II type 1 receptor gene polymorphisms on risk of myocardial infarction. Lancet 1994;344:910-13.

12 Fatini C, Abbate R, Pepe G, et al. Searching for a better assessment of the individual coronary risk profile. The role of angiotensin-converting enzyme, angiotensin II type 1 receptor and angiotensinogen gene polymorphisms. Eur Heart $\mathcal{F} 2000 ; 21: 633-8$.

13 Jukema JW, Bruschke AVG, van Boven AJ, et al. Effects of lipid lowering by pravastatin on progression and regression of coronary artery disease in symptomatic men with normal to moderately elevated serum cholesterol levels. The "regression growth evaluation statin study" (REThe "regression growth evaluation station 1995;91:2528-40.

14 Rigat B, Hubert C, Corvol P, et al. PCR detection of the insertion/deletion polymorphism of the human angiotensin enzyme (DCP 1) (dipeptidyl carboxypeptidase 1). Nucleic Acids Res 1992;20:1433.

5 Shanmugan V, Sell KW, Saha BK. Mistyping ACE heterozygotes. PCR Methods and Applications 1993;3:1201.

16 Hingorani AD, Brown MJ. A simple molecular assay for the $\mathrm{C}^{1166}$ variant of the angiotensin II type 1 receptor gene. Biochem Biophys Res Commun 1995;213:725-9.

17 Diet F, Pratt RE, Berry GJ, et al. Increased accumulation of tissue ACE in human atherosclerotic coronary artery tissue ACE in human atherosclero

18 Berkenboom G. Unstable atherosclerotic plaque. Pathophysiology and therapeutic guidelines. Acta Cardiol 1998; 53:235-41. 
19 Ohishi M, Ueda M, Rakugi H, et al. Enhanced expression of angiotensin-converting enzyme is associated with progression of coronary atherosclerosis in humans. $f$ Hyperten 1997; 15:1295-302.

20 Schieffer B, Schieffer E, Hilfiker-Kleiner D, et al. Expression of angiotensin II and interleukin 6 in human coronary atherosclerotic plaques: potential implications for inflammation and plaque instability. Circulation 2000;101:1372-8.

21 Pastore L, Tessitore A, Martinotti S, et al. Angiotensin II stimulates intercellular adhesion molecule-1 (ICAM-1) expression by human vascular endothelial cells and increases soluble ICAM-1 release in vivo. Circulation 1999; 100:1646-52.

22 Samani NJ, Martin DS, Brack M, et al. Insertion/deletion polymorphism in the angiotensin-converting enzyme gene and risk of restenosis after coronary angioplasty. Lancet 1995;345:1013-16.

23 O'Malley JP, Maslen CL, Illingworth DR. Angiotensinconverting enzyme DD genotype and cardiovascular converting enzyme DD genotype and cardiovascular culation 1998:97:1780-3.

24 Henrion D, Amant C, Benessiano J, et al. Angiotensin II type 1 receptor gene polymorphism is associated with an increased vascular reactivity in the human mammary artery in vitro. $\mathcal{F}$ Vasc Res 1998;35:356-62.

25 van Geel PP, Pinto YM, Voors AA, et al. The angiotensin II type 1 receptor $\mathrm{A} 1166 \mathrm{C}$ gene polymorphism is associated with an increased response to angiotensin II in human arteries. Hypertension 2000;35:717-21.

26 The Heart Outcomes prevention Evaluation Study Investigators. Effects of an angiotensin converting-enzyme inhibitor, ramipril, on cardiovascular events in high-risk patients. N Engl F Med 2000;342:145-53.

27 Talmud PJ, Watts GF, McBride S, et al. Angiotensin converting enzyme gene polymorphism and the course of angiographically defined coronary artery disease. Atheroangiographically defined

28 Ludwig E, Corneli PS, Anderson JL, et al. Angiotensin converting enzyme gene polymorphism is associated with myocardial infarction but not with development of coronary stenosis. Circulation 1995;91:2120-4.

29 Gardemann A, Nguyen QD, Humme J, et al. Angiotensin II type 1 receptor A1166C gene polymorphism. Absence of an association with the risk of coronary artery disease and myocardial infarction and of a synergistic effect with angiotensin-converting enzyme gene polymorphism on the risk of these diseases. Eur Heart F 1998;19:1657-65.

\section{Commentary}

This paper by van Geel and colleagues is a large prospective substudy within the REGRESS trial of lipid lowering treatment with pravastatin. Polymorphism of the angiotensin I converting enzyme (ACE) and the angiotensin II type 1 receptor (AT1 receptor) were examined in relation to the occurrence of ischaemic events in nearly 800 men. Although ACE DD genotype and AT1 receptor CC genotype did not influence response to lipid lowering treatment or plaque progression, men with both DD and CC genotypes showed a significantly greater risk of suffering an ischaemic event in the two year follow up period. This observation is suggestive of a functional interaction between the two genotypes. The authors speculate that increased activity of the renin angiotensin system could contribute to plaque instability through pro-oxidant and inflammatory mechanisms. Consideration of these data in the light of the recent HOPE study (confirming a reduction in ischaemic events in patients taking ACE inhibitor treatment) suggests that further investigation of the contribution of the renin-angiotensin system to ischaemic heart disease may be very rewarding.

G F BAXTER Associate Editor

\section{WEB TOP 10}

www.heartjnl.com

These articles scored the most hits on Heart's web site during January 2001

1 Guideline for the management of patients with acute coronary syndromes without persistent ECG ST segment elevation February 2001;85:133-42.

2 Acute pulmonary embolism 1: pathophysiology, clinical presentation, and diagnosis $M$ Riedel

February 2001;85:229-40 (Education in Heart)

3 Cardiac tumours: diagnosis and management

LM Shapiro

February 2001;85:218-22 (Education in Heart)

4 Joint British recommendations on prevention of coronary heart disease in clinical practice

December 1998;80(suppl 2):S1-29

5 Homocysteine and coronary heart disease in the Caerphilly cohort: a 10 year follow up UB Fallon, Y Ben-Shlomo, P Elwood, $7 B$ Ubbink, $G$ Davey Smith

February 2001;85:153-8 (Cardiovascular medicine)

6 Safe discharge from the cardiac emergency room with a rapid rule-out myocardial infarction protocol using serial CK-MBmass $R$ Bholasingh, Rf de Winter, $7 C$ Fischer, RW Koster, RfG Peters, GT Sanders

February 2001;85:143-8 (Cardiovascular medicine)

7 Balloon valvuloplasty

A Vahanian

February 2001;85:223-8 (Education in Heart)

8 Sex differences in investigation results and treatment in subjects referred for investigation of chest pain

$Y$ Wong, A Rodwell, S Dawkins, S A Livesey, I A Simpson

February 2001;85:149-52 (Cardiovascular medicine)

9 Importance of rate control or rate regulation for improving exercise capacity and quality of life in patients with permanent atrial fibrillation and normal left ventricular function: a randomised controlled study $T$ Levy, $S$ Walker, $M$ Mason, P Spurrell, $S$ Rex, $S$ Brant, V Paul

February 2001;85:171-8 (Cardiovascular medicine)

10 Long term results of heart transplantation in patients with amyloid heart disease $S W$ Dubrey, $M$ M Burke, A Khaghani, $P N$ Hawkins, $M H$ Yacoub, $N$ R Banner February 2001;85:202-7 (Interventional cardiology and surgery) 